Revista do SELL

v. 6 , no. 2

ISSN: $1983-3873$

\title{
SOBRE VERDADE E MENTIRA, POR FUNES, EL MEMORIOSO. A INVENÇÃO DE UM DIÁLOGO ENTRE NIETZSCHE E BORGES ${ }^{1}$
}

\author{
ON TRUTH AND LIES BY FUNES, EL MEMORIOSO. THE INVENTION OF A \\ DIALOGUE BETWEEN NIETZSCHE AND BORGES
}

\author{
Heirisgleides Souza Teixeira \\ Universidade Estadual de Campinas
}

\begin{abstract}
RESUMO: Este trabalho propõe uma aproximação entre Jorge Luis Borges e F. Nietzshe, a partir de algumas reflexões sobre tempo, memória e linguagem que aparecem em seus textos. Precisamente a aproximação se dá entre o conto do escritor argentino, "Funes, el memorioso", e o ensaio do filósofo Sobre verdade e mentira em sentido extramoral. A invenção ficcional, que cria uma personagem com a memória de um deus, reproduz quase que textualmente passagens do ensaio filosófico, de modo que ambos se aproximam no que diz respeito à limitação da memória humana. Esquecemos e por isso mentimos cada vez que pronunciamos uma simples palavra, como mesa. Mas é também porque esquecemos que é possível pensar, gerar conhecimento e literatura. A crítica à desmemória e também à linguagem limitada torna-se então um elogio da literatura, que lida com a imprecisão e, se desfazendo das metáforas desgastadas, gera novas inusitadas perspectivas sobre a "realidade".Esta, como veremos, se pensada a partir dos autores que aqui aproximamos, só poderá ser grafada entre aspas, de modo que as fronteiras entre o que é tido como real e tido como ficcional se diluem em ambos os textos.
\end{abstract}

ABSTRACT: This paper proposes an approach between Jorge Luis Borges and F. Nietzshe as from some thoughts about time, memory and language that appear in his writings. Accurately the approach is between the short story by the Argentine writer, "Funes el memorioso," and the Philosopher's essay On Truth and Lie in an Extra-Moral Sense. The fictional invention which creates a character with the memory of a god, reproduces almost verbatim passages from philosophical essay, so that both approach with regard to the limitation of human memory. We forgot and therefore we lied every time we speak a single word, like table. But it is also because we have forgotten that it is possible to think, generate knowledge and literature. The criticism of "miss of memory" and also to the limited language then becomes a praise of literature that deals with the vagueness and getting rid of worn metaphors, generates new unusual insights into "reality". This, as we shall see, if considered from the authors who approach here can only be spelled in quotes so that the boundaries between what is considered real and fictional are dissolved in both texts.

\section{Introdução}

A consciência do tempo e, com ela, da morte, é um importante fator que diferencia o homem dos outros animais e da natureza, de modo geral, que são atemporais. E é também, de outro lado, o que nos priva da eternidade. Tal consciência é possível somente porque temos memória. Em muitos de seus escritos, Jorge Luis Borges sustenta essa tese.

\footnotetext{
${ }^{1}$ Este texto é uma releitura de parte da minha dissertação de mestrado sobre as concepções de tempo e memória em Jorge Luis Borges. Naturalmente, com a passagem do tempo, avulta outra perspectiva acerca dos textos aqui apresentados, embora muito tenha sido extraído do corpo da pesquisa anterior.
} 


\section{Revista do SELL}

v. 6 , no. 2

ISSN: $1983-3873$

É o caso, por exemplo, do poema "Isidoro Acevedo". Nos últimos versos, o poeta diz não ter entendido a notícia da morte do seu avô, que lhe foi dada por meio de uma metáfora - fez uma viagem para longe - quando ainda era bem pequeno. Como não sabia o que era a morte, o menino perambulou muitos dias pela casa procurando o "abuelo": "yo era chico, yo no sabía entonces de muerte, yo era inmortal" (BORGES, 1929, p. 96).

Assim como a criança no poema, ainda não atingida pela consciência e pela mortal memória, os animais são frequentes representações do eterno no sentido de atemporal na obra de Borges, porque jamais chegam a essa consciência. No conto "El Sur", por exemplo, o personagem Dalhmann encontra-se em um café onde havia um animal - um enorme gato que se deixava acariciar pelos que por lá passavam:

Pidió una taza de café, la endulzó lentamente, la probó (ese placer le había sido vedado en la clínica) y pensó, mientras alisaba el negro pelaje, que aquel contacto era ilusorio y que estaban como separados por un cristal, porque el hombre vive en el tiempo, en la sucesión, y el mágico animal, en la actualidad, en la eternidad del instante (BORGES, 1944, p. 636).

Por que essa reflexão surge nesse momento em que Dahlmann sai do hospital? Enquanto espera pelo trem, a personagem ocupa o pouco tempo que lhe resta na estação saboreando um café, um prazer que lhe foi negado durante os dias (que pareceram séculos, ele diz) em que esteve internado. É que nesse momento, assim como o animal, Dahlmann concentra-se apenas no instante, naquele momento ínfimo no qual nada interessa a não ser o sabor mesmo do café, seu aroma, o prazer de tomá-lo. Pensar sobre esse momento já não é vivê-lo, lembrar-se dele é temporalizá-lo e, assim, admitir que ele já passou, está perdido.

Borges é um autor que joga com esses conceitos tão caros e tão sedutores para os homens, como ser imortal e ter uma memória infinita. Esses anseios, tão pretensiosos quanto ingênuos, são levados ao extremo em histórias fantásticas, que nos convidam a pensar na nossa condição, no que nos torna humanos. No conto "El inmortal", por exemplo, a imortalidade, que parece tão atraente e ao mesmo tempo tão distante e proibida, é apontada como algo banal, comum na natureza, sendo o homem a única exceção: "Ser inmortal es baladí; menos el hombre, todas las criaturas lo son, pues ignoran la muerte; lo divino, lo terrible, lo incomprensible, es saberse inmortal" (BORGES, 1949, p. 650).

Já a memória é tão necessária e desejada que, sabedores da sua fragilidade, criamos artefatos para ampliá-la, para guardar aquilo de que não queremos ou não 


\section{Revista do SELL}

v. 6 , no. 2

ISSN: $1983-3873$

devemos nos esquecer. Para Borges, criamos alguns instrumentos para estender fisicamente nossos corpos (são exemplo disso o microscópio - que aumenta a visão - e o arado - que amplia o braço). Mas a mais assombrosa invenção, aponta, é o livro, pois "o livro é uma extensão da memória e da imaginação".

E como seria ter uma memória infinita de fato? Um chamado Funes, personagem criada pelo autor, nos permite uma curiosa visão desse desejo que, se realizado, tornar-seia uma danação. É sobre essa personagem e suas reflexões a matéria de discussão deste texto. Para tanto, propomos uma aproximação com o ensaio escrito por F. Nietzsche, Sobre verdade e mentira em sentido extramoral. Com ele, podemos discutir a questão da memória e do esquecimento, bem como os limites (aqui entendidos como limitações) da linguagem criada pelo homem.

A aproximação dos dois autores visa mostrar um Borges leitor de Nietzsche, um leitor que joga com a questão posta pelo filósofo; que imagina a condição de possibilidade, como um e se... "e se o homem passasse a ter memória o bastante para poder nomear um a um todos os seres? Assim chegamos à representação do impossível Funes. Importa mostrar essa apropriação do pensamento do filósofo, porque torna-se exemplar do modo como a literatura transforma poeticamente a tradição filosófica.

Tendo por base o trabalho de Emir Monegal, podemos dizer que Borges desenvolve uma poética da leitura e se apresenta muito frequentemente como leitor de outros autores. Podemos então pensar Borges produzindo um texto que expõe sua leitura de Nietsche; o texto de Borges - o conto - produz efeitos de sentido diversos, portanto leituras, como a que ora tentamos apresentar neste trabalho. Por seu turno, este trabalho, uma vez lido por outras pessoas, poderá também, quem sabe, provocar outras tantas reações como, por exemplo, motivar a leitura do conto de Borges ou do ensaio de Nietzche, fechando um ciclo, que se abre a outras novas e infindáveis possibilidades, mas também promovendo, cada vez, um maior distanciamento entre o objeto e sua representação.

Uma segunda motivação para este trabalho, mas ainda dentro da questão da apropriação da filosofia pela literatura, é mostrar que esse jogo realizado pelo autor argentino resulta, no presente caso, não em uma crítica severa ao homem de ciência, como queria Nietzsche em seu ensaio, mas em um elogio à literatura. Isso porque a invenção de Borges evidencia que, de fato, a linguagem é metafórica, imprecisa. Mas tais adjetivos, se parecem problemáticos para a ciência, soam à literatura como elogio, pois é essa 


\section{Revista do SELL}

v. 6 , no. 2

ISSN: $1983-3873$

imprecisão que torna possíveis as múltiplas leituras a que nos referimos no parágrafo anterior.

\section{O vertiginoso mundo de Funes}

Neste item, apresentamos comentário rente ao texto de Borges, destacando pontos que interessam para o diálogo com Nietzsche no item posterior. Em "Funes, el memorioso", Borges (pois esse é o nome do narrador) conta a história de Ireneo Funes, que possuía uma extraordinária capacidade de se recordar de tudo, de modo absoluto, com uma precisão de detalhes infinita. Tão incrível era a sua memória que o narrador começa com dificuldade seu relato. Sua primeira afirmação - "Lo recuerdo" - é interrompida por uma ressalva: "lo recuerdo (creo)" (BORGES, 1944, p. 583). Isso porque, para o narrador, somente um homem pode pronunciar esse "verbo sagrado", o compadrito uruguaio, com quem esteve umas duas ou três vezes.

Na primeira vez em que viu Funes, ambos corriam em direções contrárias e não se falaram; mas Borges soube naquele momento que o jovem avistado era "mentado por algunas rarezas como la de no darse con nadie y la de saber siempre la hora, como um reloj". Sem ajuda de aparelhos ou do sol, Funes acompanha o tempo segundo a segundo:

Bernardo le gritó imprevisiblemente: “¿Qué horas son, Ireneo?" Sin consultar el cielo, sin detenerse, el otro respondió: "Faltan cuatro minutos para las ocho, joven Bernardo Juan Francisco" (BORGES, 1944, p. 584).

Esse estranho dom apenas antecipa a extrema capacidade de Funes, revelada após um acidente que o deixará paralisado. Três anos depois, ao saber que Borges havia levado para a pequena cidade de Fray Bentos alguns livros para estudar latim², Funes the endereça uma carta, na qual se lembra do fugaz encontro "del día 7 de febrero del año 84 " (dia em que se encontraram pela primeira vez) e solicita um dos livros de empréstimo e um dicionário, pois ainda não sabia latim, prometendo devolvê-los "casi inmediatamente". Muito ironicamente, Borges encaminha os volumes solicitados, pois é obviamente impossível que alguém seja capaz de aprender uma língua em tão pouco tempo, uma impossibilidade também representativa do desejo de muitos de nós, uma sedutora impossibilidade.

\footnotetext{
${ }^{2}$ Os livros eram "De viris ilustribus de lhomond, el Thesaurus Quicherat, los comentarios de Julio Cesar y un volumen impar de la Naturais historia de Plinio".
} 


\section{Revista do SELL \\ v. 6 , no. 2 \\ ISSN: $1983-3873$}

Apenas três dias depois de ter encaminhado os livros, Borges vai ao encontro de Funes para recebê-los de volta. Em meio à escuridão, ouviu alta e jocosa a voz de Ireneo, tal como da primeira vez que o ouvira, anos antes, mas agora ele falava em latim. De início assombrado, o narrador julga indecifráveis e intermináveis as palavras ouvidas, que "formaban el primer párrafro del vigésimo cuarto capítulo del libro séptimo de La Naturalis historia. La materia de ese capítulo es la memoria; las últimas palabras fueron ut nihil non iis dem verbis reddereturauditum", cuja tradução aproximada é: nada do que foi uma vez ouvido pode ser repetido com as mesmas palavras.

Ireneo cita "los casos de memoria prodigiosa registrados en la Naturalis Historia" Ciro, Mitríades Eupator, Simônides, Metrodoro - e "se maravilló de que tales casos maravillaran". Aqui fazemos uma pequena digressão para recontar uma dessas anedotas históricas, citadas em Lete, livro de Harald Weinrich (2001, p. 30), em que o esquecimento, e não a lembrança, está no centro da discussão. Mas, sendo a lembrança a face oposta do esquecimento, o autor não pode escapar de discuti-la. E cita, então, um dos casos que admiraram Funes: o caso do poeta grego Simônides, conhecido como pai da mnemotécnica. Este, participando de uma festa em homenagem a um boxeador, é repentinamente chamado para fora do salão por dois rapazes que querem dizer-Ihe algo. Nesse momento, o teto do salão desaba e todos os convidados morrem. Simônides, por ter uma excelente memória visual, ajuda a reconhecer os mortos, pois se "recorda exatamente em que local da mesa de banquete se sentara cada convidado. Essa memória espacial permite-Ihe identificar os mortos segundo sua localização no aposento".

A admirável memória de Simônides, no entanto, nem de longe representa o que se tornou a memória de Funes. Por isso, ele argumenta que antes do episódio que o deixara inválido, era, como todos os humanos, "un ciego, un sordo, un abombado, un desmemoriado [...] diecinueve años había vivido como quien sueña: miraba sin ver, oía sin oir, se olvidaba de todo, de casi todo", daí pensar que teria sido benéfica a queda e a imobilidade, preço mínimo para a tamanha aquisição: "ahora su percepción y su memoria eran infalibles".

Seguem-se vários exemplos daquilo que é a memória de Funes uma memoria infalível, totalizante, inumana:

Me dijo: Más recuerdos tengo yo solo que los que habrán tenido todos los hombres desde que el mundo es mundo. Y también: Mis sueños son como 


\section{Revista do SELL}

v. 6 , no. 2

ISSN: $1983-3873$

la vigilia de ustedes. Y también hasta el alba: Mi memoria, señor, es como un vaciadero de basuras.

Ao olhar para uma flor, Funes era capaz de vê-la "como nadie la ha visto, aunque la mirara desde el crepúsculo del día hasta el de la noche, toda una vida entera". Sua percepção era tão precisa que achava absurdo que as coisas tivessem o mesmo nome sempre, a despeito da ação do tempo sobre elas, uma ação que ele percebia segundo a segundo. Por isso, cada flor, cada folha de cada árvore, cada minúscula pedrinha no chão, para ele tudo deveria ter um nome próprio. Mas isso ainda não bastava.

Ver a flor era diferente de lembrar-se dela e por isso a flor vista e a flor lembrada deveriam ter nomes diferentes. E também a lembrança da lembrança da flor, e assim ao infinito. Ademais, cada vez que via a flor, podia perceber os avanços do tempo sobre ela, o quanto mudara a cada segundo... e surpreendia-se cada vez que via palma da sua mão.

Ao comentar a supermemória de Funes, o narrador lembra Locke que, no séc. XVII, tentou criar um idioma em que cada coisa tivesse seu nome próprio, mas abandonou tal ideia. Locke mostrava que a linguagem é fruto de generalizações, pensamento que persiste em Nietzsche (1873, p. 31), como veremos. Para Funes, a possibilidade de criar um idioma, como Locke, em que cada coisa tivesse seu nome próprio, é anulada porque chegava ao extremo de não admitir que um cachorro visto de frente tivesse o mesmo nome de quando visto de lado quinze minutos depois, ainda menos que ele tivesse o mesmo nome a vida inteira.

Não apenas a língua, mas o sistema numérico também the parece a Funes inaceitável. Aborrecido porque utilizamos, para o número 33, por exemplo, "dos signos y tres palabras, en lugar de una sola palabra y un solo signo", Funes cria um outro sistema:

En lugar de siete mil trece, decía (por ejemplo) «Máximo Pérez»; en lugar de siete mil catorce, «El Ferrocarril»; otros números eran «Luis Melián Lafinur», «Olimar», «azufre», «los bastos», «la ballena», «el gas», «la caldera», «Napoleón», «Agustín de Vedia». En lugar de quinientos, decía «nueve». Cada palabra tenía un signo particular, una especie de marca; las últimas eran muy complicadas... (BORGES, 1944, p. 547).

A proposta de Funes parece inaceitável também a nossos olhos e é assim que a literatura de Borges costuma subverter a lógica do mundo automatizado, do mundo cotidiano, das palavras habituais, que não causam qualquer estranheza ao ouvinte. Pelo 


\section{Revista do SELL}

v. 6 , no. 2

ISSN: $1983-3873$

viés da dessemelhança, proporciona reflexões inusitadas, as quais nos levaram ao não menos supreendente filósofo F. Nietzshe.

A supermemória ou a impossibilidade de pensar

Em Sobre verdade e mentira em sentido extramoral, Nietzsche afirma que a linguagem não pode ser correspondente à verdade, já que as palavras não são as próprias coisas; palavras são metáforas desgastadas pelo uso contínuo e repetitivo, são "convenções consolidadas", conceitos automatizados, que surgem do apagamento das diferenças, das particularidades dos objetos, tratando-os como iguais quando, na verdade, são apenas semelhantes:

Todo conceito surge pela igualação do não-igual. Tão certo como uma folha nunca é totalmente igual a outra, é certo ainda que o conceito de folha é formado por meio de uma arbitrária abstração dessas diferenças individuais, por um esquecer-se do diferençável, despertando então a representação, como se na natureza, além das folhas, houvesse algo que fosse "folha", tal como uma "fórmula primordial de acordo com a qual todas as folhas fossem tecidas, desenhadas, contornadas, coloridas, encrespadas e pintadas, mas por mãos ineptas, de sorte que nenhum exemplar resultasse correto e confiável como cópia autêntica da forma primordial (NIETZSCHE, 1873, p. 35-36) .

É esse também o exemplo dado pelo narrador borgeano acerca de Ireneo Funes. Como consegue perceber a diferença entre todas as folhas cada vez que as vê, não pode admitir que todas tenham o mesmo nome: "em efecto, Funes no solo recordaba cada hoja de cada árbol, de cada monte, sino cada una de las veces que la había percibido o imaginado" (BORGES, 1944, p. 549). Mas uma memória dessa natureza torna o raciocínio uma impossibilidade.

Como não pode se esquecer, a super-memória de Funes retém cada instante individualmente, e cada instante é inteiramente diverso; por isso a repetição não cabe no seu sistema numérico, por isso cada folha de cada árvore deveria ter um nome diferente e também um nome deveria ser-lhe atribuído para cada momento em que ela fosse lembrada, pois aí já não seria a folha, mas a lembrança da folha, e depois da lembrança da lembrança da folha e assim sucessivamente.

Cada exemplo no conto que envolve a memória total de Funes torna a dádiva danação. Nietzsche (1873, p. 26) critica o homem da ciência - o soberbo inventor do conhecimento, dono da verdade - por "esquecer" as diferenças entre os indivíduos e, por 


\section{Revista do SELL}

v. 6 , no. 2

ISSN: $1983-3873$

isso, generalizar, quer dizer levar em consideração umas poucas similaridades e apagar uma infinidade de dessemelhanças. Por necessidade, o homem "mente" cada vez que enuncia o que quer que seja. Para o filósofo, a maior prova da imprecisão da linguagem é que "dispostas lado a lado, as diferentes línguas mostram que, nas palavras, o que conta nunca é a verdade, jamais uma expressão adequada: pois, do contrário, não haveria tantas línguas".

Imaginemos, então, esse ser capaz de perceber e reter na memória cada desenho, cada contorno e cada cor de cada folha. Essa extrema capacidade de rememorar elimina, por consequência, a capacidade de pensar. De fato, diz Borges, para Funes era impossível pensar porque para ele era impossível esquecer; no seu sistema numérico não cabe a repetição, pois para que a linguagem pudesse apreender o mundo - aí apresentado como caótico - teria que ser ela também o próprio caos. Borges, criador de caos, inventa um ser para quem o caos é o mundo, um mundo impossível de ser traduzido, explicado por palavras, pois que era "casi incapaz de ideas generales, platónicas". Em contrapartida, era "el solitario y lúcido espectador de un mundo multiforme, instantáneo y casi intorelablemente preciso".

Para Nietzsche, repetições são o que nos atraem e não gostamos da instabilidade. Apreciamos o sistema numérico e as "representações de tempo e de espaço". Funes é, todo o contrário, representação do que não somos. Por isso, nos faz pensar no quão instável é o mundo e como procuramos homogeneizá-lo.

Segundo Prigogine, no século XVIII, quando "Teologia e ciência convergiam", havia a ideia de que Deus poderia ver o presente, o passado e o futuro de uma só vez (PRIGOGINE, 1996, p. 20). É essa visão do todo que possui Funes, ou seja, num instante, ele se lembra de tudo o que aconteceu desde sempre e de tudo o que existe, tornando-se, nesse sentido, similar a um deus; entretanto, o que Funes vê não pode por ele mesmo ser descrito, justo porque para ele tudo é simultâneo. Ser como um Deus é entender, na totalidade, as leis do universo. Para Funes, entretanto, não há leis, ou melhor, a lei é o caos, a instabilidade, a modificação do mundo a cada instante, a impossível classificação, o eterno devir.

Se, por um lado, sua memória invencível the tornou capaz de aprender qualquer coisa sem esforço, por outro, a tormenta da super-consciência não Ihe permitia dormir. "Dormir es distraerse del mundo". E também era impossível pensar: "pensar es olvidar 


\section{Revista do SELL}

v. 6 , no. 2

ISSN: $1983-3873$

diferencias, es generalizar, abstraer. En el abarrotado mundo de Funes no había sino detalles, casi inmediatos"3.

Sono e vigília também figuram no diálogo de Funes com o narrador borgeano. Efetivamente, Funes não pode dormir. Como uma "metáfora del insomnio", Funes não é apenas o que se lembra, mas também o que nunca esquece e que nunca se distrai. Entendendo-o sob o ponto de vista de Nietzsche, o sonho de Funes pode se equiparar aos estados despertos do homem que pensa ser consciente e conhecedor da verdade, mas que vive um mundo cujo caos é ordenado pelos conceitos que ele mesmo elabora. Os sonhos subvertem a ordem, não obedecem à lógica, fogem do controle e, portanto, negam a estabilidade das coisas. Por isso também podemos propor que Funes desperto é como os homens sonhando. Passeiam diante dele todas as formas assumidas pela fumaça de uma chama e de tudo ele se recorda. E por serem todas díspares, não pode definir o que seria mais relevante e, assim, generalizar. "Pensar es olvidar diferencias, es generalizar, abstraer", afirma narrador de Funes, uma vez mais dialogando com Nietzsche (1873, p. 66), para quem o conhecimento só é possível com os procedimentos de "separação, delimitação e abreviação". É impossível para um homem conhecer tudo de modo absoluto. De fato, segundo o filósofo, a despeito de as palavras não serem as coisas mesmas, nem mesmo de serem naturais e ainda de não corresponderem sequer às coisas que designam, enfim, a despeito de o homem "mentir" cada vez que enuncia algo, ele "age conforme hábitos seculares - e precisamente por meio dessa inconsistência, justamente mediante esse esquecer-se atinge o sentimento de verdade" (NIETZSCHE, 1873, p. 37, grifo do autor).

Ao esquecer que cria nada menos que metáforas, o homem se sente impelido a criar novas metáforas, se apraz em criar mundos ditos ficcionais, por meio da arte, de um modo geral (NIETZSHE, 1873). A arte, portanto, desconstrói e reinventa "o mundo real". Tendo em vista essa consideração e não nos esquecendo de que o texto de Borges é, sobretudo, uma produção artística, podemos pensar no mundo de Funes como uma inversão daquilo que entendemos como realidade. Com efeito, Funes não pode pensar porque não pode esquecer, e isso já é todo o contrário do que geralmente somos.

\footnotetext{
${ }^{3}$ É curiosa a passagem que Wheinch cita de P. Valery, ao falar do esquecimento: "adormecer significa esquecer. Por isso, não poder esquecer é comparável à insônia, e Nietzsche sofria de ambas as coisas”. Essa afirmação parece nos autorizar ainda mais quanto às aproximações que aqui propomos.
} 


\section{Revista do SELL}

v. 6 , no. 2

ISSN: $1983-3873$

\section{O defeito da linguagem ou o elogio da literatura}

Como vimos, os dois sistemas criados por Funes são incompreensíveis porque fogem à lógica, à lógica do nosso sistema internalizado e automatizado, tido como verdadeiro. Mas é aí que a ficção parece realizar uma outra inversão, tornando não o de Funes, mas o nosso um mundo ininteligível. Seguimos aqui a linha de raciocínio de Isabel Stratta (2005), para quem Borges não se preocupa em dar à sua criação literária uma função, a não ser a de "proporcionar a sus lectores un tipo particular de felicidad de la forma", algo que estaria oposto ao mundo caótico em que vivem. Nesse caso, o caos que rege os sistemas de Funes, caóticos porque arbitrários (?), é o mesmo que se aplica aos nossos sistemas "reais".

Para Pelegrini (2009), "la teoría de Borges acerca del lenguaje es nada más ni nada menos que una consideración filosófica sobre los límites del lenguaje". Defendemos, no entanto, que a escritura borgeana não se presta simplesmente a uma crítica à linguagem. Nela, o caráter maleável da palavra vai muito além do que o já mais que abalado senso comum pode prever. Como Funes, que inventa sistemas novos de linguagem, a literatura de Borges explora as possíveis relações entre as palavras e, como afirma Ricoeur acerca da metáfora viva, produz aproximações que pareceriam impossíveis e, por outro lado, constrói verdadeiros abismos entre semelhantes.

Mais que evidenciar o limite, Borges explora esse 'defeito' da linguagem e o torna qualificativo da própria literatura, multiplicando ao infinito os possíveis significados, desautomatizando 4 nossos esquemas. Atentemos, então, para a afirmação de Costa Lima (1980, p. 67) sobre o ambiente cultural no qual estamos inseridos; pensemos nesse cotidiano como o lugar onde as razões do senso comum nos envolvem como se estivéssemos vestidos "com roupas muito leves, tão leves que a pele não sente que as transporta". Nesse meio, a carga simbólica que carregamos cotidianamente passa despercebida, como se fosse natural; os pensamentos, as sensações, o tempo, os modos de falar e de nos comportar -tudo são símbolos. Por isso, para o crítico, "em Borges, literatura e realidade estreitam seus laços e dizer de uma é falar da outra" (COSTA LIMA, 1980, p. 237)

Símbolos: Biblioteca, Aleph, zahir, ou mesmo lua, tigre... Tais palavras são exemplos do que, em nossa pesquisa de mestrado, denominamos imagens da totalidade na obra de

\footnotetext{
${ }^{4}$ Tomo de empréstimo a expressão empregada pelo formalista russo V. Chklovski.
} 


\section{Revista do SELL}

v. 6 , no. 2

ISSN: $1983-3873$

Jorge Luis Borges. São palavras que, nas situações narradas em seus contos, sugerem uma multiplicidade de eventos, muitas vezes ocorridos em durações diversas, mas presenciados pelos narradores ou personagens de modo simultâneo. Passado, presente e futuro são sobrepostos, mas perfeitamente diferenciados: "decir el tigre es decir los tigres que lo engendraron, los ciervos y tortugas que devoró, el pasto de que se alimentaron los ciervos, la tierra que fue madre del pasto, el cielo que dio luz a la tierra" (BORGES, 1949, p. 719). São duas as palavras de Borges para essa visão: horror e admiração. O literário tem então uma função: pesar sobre o corpo a roupa, tornar rarefeito o ar, incomodar para fazer descobrir, ou redescobrir.

O sistema da linguagem, com suas generalizações, não traduz as coisas como realmente são, daí tornar-se impossível falar com precisão o que foi uma vez visto, pois a linguagem não abarca a simultaneidade, a linguagem é sucessiva. As palavras "mundo, todo, universo" já não são as únicas a figurar como imprecisas (e soberbas para lembrar Nietzshe). O vivido não corresponde jamais ao narrado. Tudo são símbolos, "símbolos de otros símbolos", como dirá Borges em um verso.

Por outro lado, a mesma imprecisão que traz a palavra torna-se matéria da criação borgeana. Com efeito, Borges, embora não invente palavras, cria outros significados para elas, significados que desestabilizam, mais uma vez, o senso comum. A biblioteca passa a ser todo o universo em seu conto; mas, no mesmo conto, afirma: em algum lugar, biblioteca "admite la correcta definición ubicuo y perdurable sistema de galerias hexagonales", ou seja, a definição exata daquilo que é descrito pelo bibliotecário no conto "La biblioteca de Babel". Mas, continua, em algum livro das infinitas prateleiras, biblioteca significa "pan o pirámide o cualquier otra cosa, y las siete palabras que la definen tienen otro valor".

Em uma das edições de Ficciones, José Luis Rodriguez Zapatero (2001, p. 02) alerta o leitor: a fronteira do mundo real - "el mundo seguro y confortable del que está hecha la vida cotidiana" - será ultrapassada. Mas não se trata de uma simples viagem pelo imaginário com a garantia do retorno ao solo firme da realidade. Em Borges, o mundo de seres imaginários invade o real, multiplicando seus sentidos possíveis e, consequentemente, transformando-o, diluindo as nossas certezas. O universo do ficcional, assim estendido, envolve o leitor, que se torna parte da ficção, ou ao contrário, a ficção torna-se parte do seu mundo. E eis que já não podemos grafar "real" sem aspas, pois tratase sobretudo de pôr em cheque a invenção/inversão da linguagem. 


\section{Revista do SELL}

v. 6 , no. 2

ISSN: $1983-3873$

Retomando Funes, vemos que lembrar-se de tudo de modo absoluto (e também esquecer-se de tudo de modo absoluto), isso parece ser a danação do homem. Por isso, é preciso esquecer e lembrar, dentre outras coisas, que a nossa linguagem não traduz o que queremos dizer. Falando da sua própria narrativa sobre Funes, Borges diz que é impossível, por meio de palavras, "representar esse mundo vertiginoso onde tudo acontece ao mesmo tempo".

A consciência absoluta de tudo não me permitiria falar a você, leitor, porque jamais poderei expressar de fato como vejo Funes, como imagino o incomunicável Aleph. De outro lado, é preciso que você se esqueça um pouco dessa imprecisão da linguagem para que, de algum modo, me entenda ou julgue entender. Assim, num complexo equilíbrio entre esquecer e lembrar, poderemos ter a feliz ilusão de que nos encontramos diante da verdade.

Tanto a narrativa de Borges quanto o ensaio de Nietsche vão de encontro à naturalização dos símbolos, pois, como vimos, tomam elementos simbólicos e verdades pré-estabelecidas e os insere na ficção, desautomatizando-os. As histórias fantásticas de Borges guardam o tom da dúvida por ele apontada diversas vezes em sua vasta obra: não sabemos se o mundo existe realmente, ou se estamos sendo sonhados, ou se estamos apenas sonhando. Mas pouco importa, na ficção, descobrir; importa especular, discutir, inquirir, conjecturar ${ }^{5}$.

Borges recria, na ficção, as considerações de Nietzsche sobre a memória, a linguagem, o conhecimento. Somos humanos porque, mais que lembrar, podemos esquecer. Harald Wheinrich (2001, p. 11) propõe, logo no início do seu Lete, história do esquecimento, a denominação obliviscens: "o homem está naturalmente sujeito à lei do esquecimento, ele é fundamentalmente um animal obliviscens".

Borges cria o memorioso Funes, que vive apenas o presente; para ele cada instante é único, porque tudo se transforma continuamente. No entanto, na invenção borgeana, ocorre uma inversão: Funes tem uma super memória, de modo que o instante é abarrotado por todas as lembranças do passado, multiplicadas ao infinito. Então, pensemos: se tudo se reduz à memória, Funes não vive apenas o passado, já que a memória é do passado, segundo a tradição clássica grega? De fato, podemos argumentar que ele se lembra de tudo e de todas as vezes que se lembrou de cada coisa, portanto vive no passado. Mas, a

\footnotetext{
5 : "Logicamente, talvez eu seja o único sonhador, e eu sonhei toda a história universal, todo o passado, todo meu próprio passado; talvez eu comece a existir neste momento" (BORGES, 1985a, p. 191)
} 


\section{Revista do SELL}

v. 6 , no. 2

ISSN: $1983-3873$

fim de contra-argumentar, o próprio narrador deixa claro que cada lembrança de Ireneo é acompanhada de todas as sensações que teve quando presenciou o evento e, se se lembra de ter sentido frio, frio é o que sente no mesmo instante. Assim, Funes se vê preso nesse presente abarrotado de lembranças, imobilizado, incapaz de pensar, incapaz de agir, desumano.

\section{Considerações finais}

Não é inédita nem rara a discussão acerca da memória e desta com a linguagem humana. É no entanto curioso que esse mesmo ponto esteja em pauta desde a antiguidade aos nossos dias, para usar uma expressão tão antiga quanto o assunto. Fato é que, pautada na visão de Borges, a memória e a linguagem são categorias que fundam o humano, como disse, são condições imprescindíveis para que exista o que chamamos de humanidade. Talvez por isso mesmo a pauta nunca saia de cena e seja sempre reatualizada, atendendo a demandas contemporâneas.

Luís Costa Lima abre o livro A literatura e o leitor (2002) debatendo algo que também procura reatualizar: o próprio texto literário. "O leitor demanda (da) literatura", diz o autor, evidenciando uma via de mão dupla, em que a literatura se reatualiza de acordo com a demanda do leitor atual, assim como atualiza os leitores. Quer isto dizer que a literatura na (não da) contemporaneidade responde a questões do seu tempo, isto é, do tempo em que é lida.

Assim, então, me coloco na posição de leitor e me pergunto que demandas pode o texto de Borges suprir na contemporaneidade. Isso quer dizer que o modo como leio, estabelecendo um diálogo com um filósofo que apresenta uma questão desconcertante sobre a nossa linguagem já constitui em si uma tentativa de responder à minha demanda. Por que é importante que nos demos conta de que a linguagem é, como querem esses dois autores, sempre uma metáfora?

É fato que devemos admitir que a linguagem como sistema constituído é imprescindível para o estabelecimento das relações entre as pessoas e também para a própria constituição do pensamento. Sob esse aspecto a primeira parte da reflexão, tanto de Nietzsche quanto de Borges, não se sustentaria, embora tenhamos visto que não se trata de propor uma destruição da linguagem nem em um nem em outro texto.

No entanto, ter ciência de que toda palavra é sempre metafórica é também garantir, minimamente, que não se pode admitir a homogeneidade do pensamento. $\mathrm{E}$ a tentativa de 


\section{Revista do SELL}

v. 6 , no. 2

ISSN: $1983-3873$

homogeneização do pensamento "gera efeitos totalitários que subordinam e fragilizam o homem". Para usar uma expressão cunhada pelo próprio Nietzsche, a homogeneização torna o homem "animal de rebanho", o que pode ser rebatido no exercício da liberdade de questionar sempre a validade da palavra dita, escrita, veiculada, seja pelo homem da ciência, seja pela política estabelecida em cada cultura, que define, entre outras coisas, o que deve ou não ser objeto da memória coletiva, definição muitas vezes imposta com violência, cujos exemplos abundam na história. Entretanto, "é preciso exercer a singularidade, é preciso ultrapassar a mediocridade dos homens domesticados, anestesiados e esquecidos de sua própria condição criadora" (BARRENECHEA; DIAS, 2013, p. 326).

“A sociedade respira e transpira representações", diz Costa Lima (1980, p. 71). Por isso, reflete Nietzsche (ou Funes?), para além de qualquer moral, mentimos porque representamos. Mas Borges torna o limite elogio quando chega a tecer possibilidades como essas: Funes vive no presente e no passado ao mesmo tempo. Borges, com quase oitenta anos, encontra-se consigo mesmo aos dezessete. O universo - que ele chama biblioteca é finito e infinito ao mesmo tempo. Não podemos admitir, dentro dos limites da razão e da linguagem tais possibilidades. Mas essa literatura, que nos tira de certa zona de conforto e nos arranca a roupa no meio da rua, nos faz olhar para o mundo e pensar que talvez só seja possível entendê-lo como "real" somente se entre aspas. É preciso estar atento.

\section{Referências}

BARRENECHEA, M. A; DIAS, M. J.E. Nietzsche e Arendt: memória e política na atualidade. Cadernos Nietzsche, v. 33, p. 301-326, 2013.

BORGES, Jorge Luis. Cuaderno San Martín [1929]. In: BORGES, Jorge Luis. Obras Completas I.Buenos Aires: Emece Editores, 2007.

Ficciones [1944]. In: BORGES, Jorge Luis. Obras Completas I.Buenos Aires: Emece Editores, 2007.

El aleph [1949]. In: BORGES, Jorge Luis. Obras Completas I.Buenos Aires: Emece Editores, 2007. Hedra, 2009.

; FERRARI, Osvaldo [1985]. Sobre os sonhos e outros diálogos. São Paulo:

Borges, Oral [1979]. In: BORGES, Jorge Luis. Obras Completas IV.Buenos Aires: Emece Editores, 2007. 


\section{Revista do SELL}

v. 6 , no. 2

ISSN: $1983-3873$

CHKLOVSKI, V. A arte como procedimento. In: EIKHENBAUM et al. Formalistas rusos. Porto Alegre: Ed. Globo, 1976.

COSTA LIMA, Luis. Mímesis e modernidade: formas das sombras. Rio de Janeiro: Edições Graal, 1980.

A literatura e o leitor: textos da estética da recepção. $2^{\mathrm{a}}$ ed. revista e ampliada. Hans Robert Jauss et. al.; coordenação, tradução e prefácio de Luiz Costa Lima. Rio de Janeiro: Paz e Terra, 2002.

PELLEGRINI, Marcelo. De obituarios y vanguardias: Joyce, Funes y el (monstruoso) mapa del lenguaje. (Criticalessay). Variaciones Borges. 26 (July 2008): 45(14). ExpandedAcademicASAP . Gale. Stanford UniversityLibraries. 3 June 2009

PRIGOGINE, llya. O fim das certezas: tempo, caos e as leis da natureza. São Paulo: Editora da UNESP, 1996.

RICOUER. Paul. A metáfora viva. São Paulo: Loyola, 2000.

ROSA, João Guimarães. Grande Sertão: Veredas. Rio de Janeiro: Nova Fronteira, 2006.

STRATTA, Isabel. Borges cuentista: lasreglasdel arte. Fragmentos, números 28/29, p. 029/039 Florianópolis/ jan - dez/ 2005.

NIETZSCHE, F. Sobre verdade e mentira em sentido extramoral [1873]. São Paulo: Hedra, 2007.

WEINRICH, Harald. Lete. Arte crítica do esquecimento. Rio de Janeiro: Civilização Brasileira, 2001 